\title{
The Spatio-Temporal Variability of Rainfall over the Agro-Ecological Zones of Ghana
}

\author{
Winifred A. Atiah* (), Leonard K. Amekudzi, Emmanuel Quansah, Kwasi Preko \\ Meteorology and Climate Science Unit, Department of Physics, Kwame Nkrumah University of Science and Technology \\ (KNUST), Kumasi, Ghana \\ Email: *winifred.a.atiah@aims-senegal.org
}

How to cite this paper: Atiah, W.A., Amekudzi, L.K., Quansah, E. and Preko, K. (2019) The Spatio-Temporal Variability of Rainfall over the Agro-Ecological Zones of Ghana. Atmospheric and Climate Sciences, 9, 527-544.

https://doi.org/10.4236/acs.2019.93034

Received: May 18, 2019

Accepted: July 23, 2019

Published: July 26, 2019

Copyright (c) 2019 by author(s) and Scientific Research Publishing Inc. This work is licensed under the Creative Commons Attribution International License (CC BY 4.0).

http://creativecommons.org/licenses/by/4.0/

\begin{abstract}
Rainfall variability plays an important role in many socio-economic activities such as food security, livelihood and farming in Ghana. Rainfall impact studies are thus very crucial for proper management of these key sectors of the country. This paper examines the seasonal and annual rainfall variability in the four agro-ecological zones of Ghana from the CHIRPS V2 rainfall time series spanning a period of 1981-2015. The rainfall indices were computed with the aid of the FClimDex package whereas the trends of these indices were further tested using the Mann Kendall trend test. The results show good agreement $(r \geq 0.7)$ between CHIRPS V2 and gauge in almost all portions of country although high biases were observed especially in DJF season over parts of the Northeastern (NE) portions of the country. The mean seasonal rainfall climatology over the country is observed to be in the range of $20-80$ $\mathrm{mm}, 60-200 \mathrm{~mm}, 100-220 \mathrm{~mm}$ and $40-180 \mathrm{~mm}$ in DJF, MAM, JJA and SON seasons respectively with high intensities of rainfall dominating Southwestern portions of the country. The trend analysis revealed positive trends of consecutive dry days in the Transition, Forest and Coastal zones and negative trends in the Savannah zone of the country. Decreasing trends of consecutive wet days are observed over the Savannah, Transition and Coastal zones whereas increasing trends dominate the Forest zone. Savannah, Forest and Transition zones show weak increasing trends of the number of heavy rainfall days whilst weak decreasing trends are observed over the Coastal zone of the country. Similarly, weak increasing trends of the number of very heavy rainfall days are observed over all the agro-ecological zones except in the Transition zone. It is observed that the annual wet day rainfall total has increasing trend in the Savannah and Forest zones of the country whereas decreasing trends cover the remainder of the zones. The trends of these indices in the agro-ecological zones were all significant at a significant value of 0.05 . This paper assessed the performance of the CHIRPS V2 rainfall data over the region and reports on
\end{abstract}


the biases in seasonal rainfall amounts which are limited in previous studies. These findings have adverse impacts on rain-fed agricultural practices, water resource management and food security over the country.

\section{Keywords}

Rainfall, Variability, Trends, Agro-Ecological Zones, Ghana

\section{Introduction}

In recent times, Ghana has been reported to be enormously impacted by periodic and protracted rainfall variability which is manifested in the form of droughts, floods, wet and dry spells among others [1] [2] [3] [4] [5]. The country greatly depends on rainfall for a manifold of their activities although agriculture, water supply and hydro-electricity production have been a major challenge [6] [7]. For instance, rainfall variability impacts the agro-ecological and growing conditions of crops and livestock. However, the agricultural practices of the country which are very predominantly rain-fed, provide employment to over $70 \%$ of citizens and about $28 \%$ of Gross Domestic Product (GDP) [8] [9]. Recent studies have also highlighted climate variability as the greatest hurdle to the realization of the first Millennium Development Goal (MDG1) of reducing poverty and food insecurity in arid and semi-arid regions of developing countries [10]. In Ghana, approximately $70 \%$ of the economically active population relies predominantly on agriculture for their livelihoods, however less than $2 \%$ of farmed land especially in Northern Ghana is irrigated [11] [12]. In consequence, the greater part of the country's agricultural production is threatened by rainfall variability. Furthermore, rainfall variability affects the hydroelectric power generation of the country as it forms about $64 \%$ of the country's power source [1] [12].

In practice, rain gauges are the most accessible and relatively reliable means through which ground rainfall could be inferred however, their numbers and distributions are fast deteriorating in the African continent [13] [14]. As a result, studies on rainfall variability especially in West Africa have been given minimal attention compared to other regions considering that the datasets needed for such studies are scarce and only available for the last few decades [15] [16]. Due to this paucity in gauge data in the region, recent studies have explored alternatives such as satellite-based and reanalysis products to perform such related studies in the region [9] [17] [18] [19] [20] [21].

In Ghana for instance, [17] analyzed the inter-annual trends and variability of rainfall over the four agro-ecological zones of the country using satellite and reanalysis products. Similarly, [9] also used the Global Precipitation Climatology Center (GPCC) data to analyze the annual and inter-decadal trends and variability of rainfall in the four agro-ecological zones of Ghana during 1901-2010. The African Rainfall Climatology (ARC2) satellite-based rainfall data have been explored to analyze rainfall trends during 1983-2012 in west-central Uganda and 
parts of equatorial Africa [18]. They found significant declining trends in rainfall in west-central Uganda during the two growing seasons of the region. In addition, [19] explored different gridded satellite precipitation datasets to analyze the trends and variability of rainfall in parts of Africa. The CPC (Climate Prediction Center) Merged Analysis of Precipitation (CMAP) data, which is a combination of gauge and satellite observations, has been applied to examine rainfall variability during 1961-2001 in the eastern African region [21].

This study uses the Climate Hazards Group Infra-red Precipitation with Station data (CHIRPS V2) to examine the seasonal and annual trends of rainfall in the four agro-ecological zones in Ghana during 1981-2015. The paper also assesses the performance of the CHIRPS V2 rainfall data over the region as well as reports on the biases in seasonal rainfall amounts which are limited in previous studies. Section two briefly describes the study area and datasets. Section three is dedicated to the methodology whilst Section four presents the results and discussion. The conclusions are presented in Section five.

\section{Study Area and Data}

\subsection{Study Area}

Ghana is located in the West African tropics (between latitude $4.5^{\circ} \mathrm{N}$ and $11.5^{\circ} \mathrm{N}$ and longitude $3.5^{\circ} \mathrm{W}$ and $1.5^{\circ} \mathrm{E}$ ) with its climate characterized by a typical tropical monsoonal climate system [17] [22]. The country shares boundaries with Cote d'Ivoire, Togo, Burkina Fasso and the Gulf of Guinea in the West, East, North and South of the country respectively and covers a total land surface of approximately $240,000 \mathrm{Km}^{2}$ [9]. The geographical location of the country makes its rainfall system highly variable spatio-temporally [12] [23]. It is the migration of the Inter-Tropical Discontinuity (ITD) that predominantly influences rainfall in the region. This meridional propagation of the ITD thus modulates the West African Monsoon (WAM). Ghana is dominated by two main rainfall seasons thus, the wet and dry. The dominance of the dry North-easterlies in the region brings about the dry season whereas the wet season is as a result of the dominance of South-westerlies in the region [9] [22] [24]. Per the Ghana Meteorological Agency (GMet) zonation, the country has been partitioned into four main agro-ecological zones thus, the Savannah, Transition, Forest and Coastal zones (see Figure 1(b)) [22]. The zonation is defined based on the climatic conditions of the various regions [9] [22]. The Savannah zone covers most of the country approximately, $63 \%$ of the total area (see Figure 1(b) Zone A). The zone is relatively dry with warm temperatures all year round compared to other zones as it receives a mean annual rainfall of about $1100 \mathrm{~mm}$. Due to the climatic conditions of the zone, it is considered a home for dispersed trees and grasses. The dominant food crops well supported and grown in this zone are sorghum, millet and maize [9]. The Transition zone on the other hand separates the dry Savannah from the Forest zone (see Figure 1(b) Zone B). As the zone is situated between the Savannah and Forest zones, it shares the climate of both zones and 


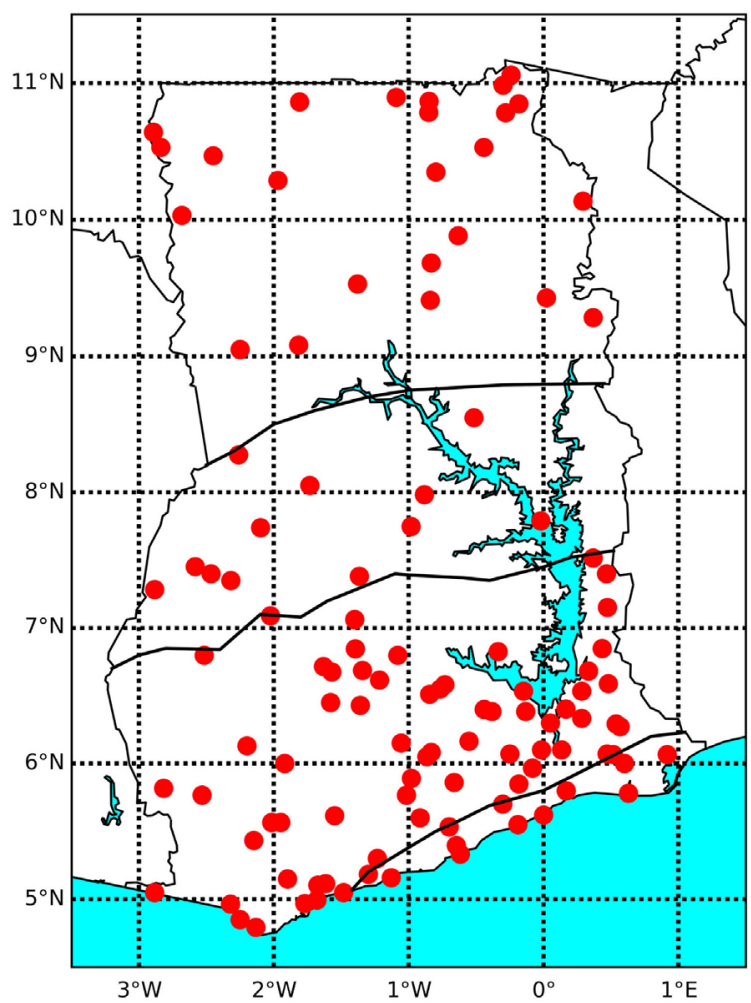

(a)

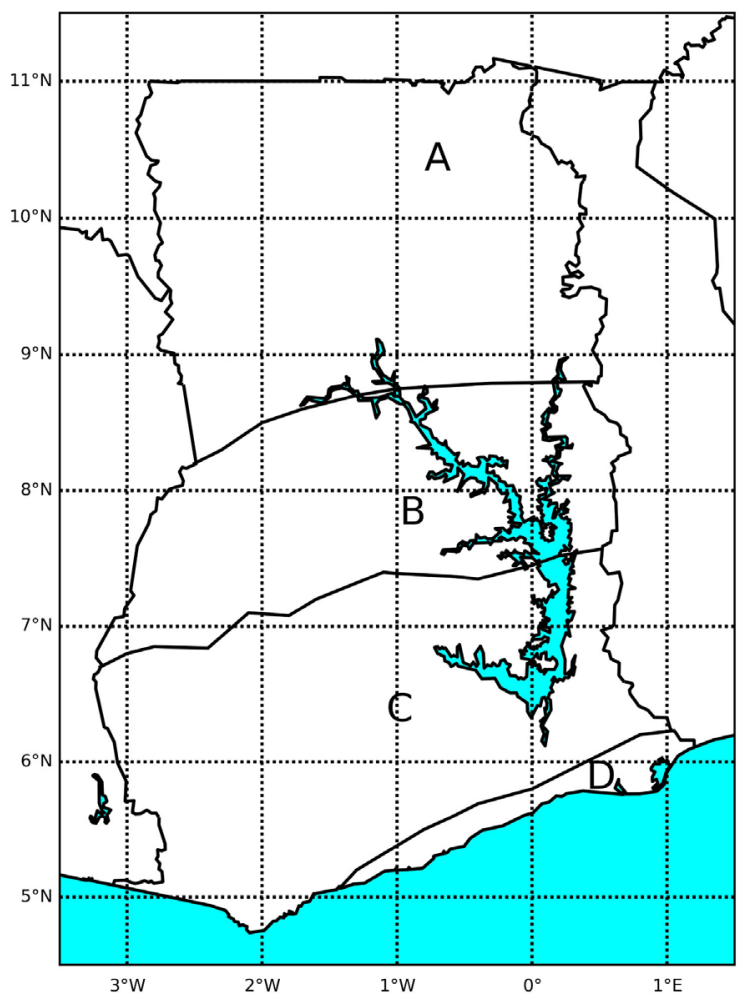

(b)

Figure 1. The study area showing the distribution of the 113-gauge stations over the country (in red) (a) with the delineation of the four agro-ecological zones of Ghana (b); Savannah zone (A), Transition zone (B), Forest zone (C) and Coastal zone (D). 
thereby known to experience a mixed weather condition. The Transition zone covers approximately $28 \%$ of the land surface of the country. This zone receives an annual mean rainfall of about $1300 \mathrm{~mm}$ per year. The zone thus supports annual food crops like, plantain, peas, corn and others [9] [17]. The Forest zone on the other hand is typically located in the Southwestern parts of the country (see Figure 1(b) Zone C). This region is wet all year round with a high annual mean rainfall amount of approximately $2200 \mathrm{~mm}$ per year.

The Coastal zone as shown in Figure 1(b) Zone D has a rainfall type which is controlled by sea-land breeze circulation. The zone inhabits sandy beaches and thus attracts tourist attention. It receives a mean annual rainfall of about 900 $\mathrm{mm}$. The rainfall patterns of the Forest, Coastal and Transition zones are typically bi-modal whereas that of the Savannah zone is uni-modal [17] [22].

\subsection{Data}

In order to achieve the purpose of this study, gauge rainfall data from the Ghana Meteorological Agency (GMet) and satellite rainfall data from the Climate Hazards Group Infra-red Precipitation with Station data (CHIRPS V2) were applied.

\subsubsection{GMet Gridded Gauge Data (GGGD)}

The gauge rainfall datasets applied in this study were obtained from a dense network of 113 GMet rain gauge stations (see Figure 1(a)). These datasets were obtained on a monthly temporal scale spanning a period of fifteen years (1998-2012). The period of data choice was mainly influenced by the availability of continuous data with less than $5 \%$ data gaps. The 113 GMet gauge stations are not evenly distributed over the country as they are relatively dense in the southern half of Ghana compared to northern half (see Figure 1(a)). The rainfall datasets were first taken through a process of homogenization to get rid of all non-climate biases and further gridded with the minimum surface curvature (MSC) gridding procedure over the country. The production and validation of the GGGD is discussed in ([24], and references therein).

\subsubsection{CHIRPS V2 Data}

CHIRPS V2 is a satellite-based rainfall data which is available in various spatio-temporal scales [25]. However, for the purpose of this study, the daily product with spatial resolution of $0.5^{\circ} \times 0.5^{\circ}$ for a period of 1981-2015 was explored. This product was selected based on its long time series, near-real time data availability, high spatio-temporal resolution and its free accessibility [25] [26]. CHIRPS V2 data is a blended rainfall product which is produced by combining data from a number of sources that include, in situ precipitation observations, pentadal precipitation climatology at grid scale, the Tropical Rainfall Measuring Mission (TRMM) 3B42 product from NASA, atmospheric model rainfall fields from NOAA Climate Forecast System (CFSv2), quasi-global geostationary thermal infrared (IR) satellite observations from the Climate Prediction Center (CPC) and the National Climatic Data Center (NCDC) (B1 IR) [25] [26] [27]. 


\section{Methodology}

Daily rainfall data was first extracted from the quasi-global CHIRPS V2 data over Ghana for the period of 1981-2015 and applied for the analysis. Since the GMet gridded rainfall data is on a monthly scale, the daily CHIRPS V2 rainfall data was averaged to monthly fields for an unbiased assessment. CHIRPS V2 was then validated with reference to gauge on monthly and seasonal timescales for a period of 15 years (1998-2012) over the entire country and in the four agro-ecological zones (Savannah, Transition, Forest and Coastal) (see Figure 1(b)). The quality of the data was further assessed using the Pearson correlation coefficient, bias, mean difference statistical measures applied in [9] [22] [24]. The Pearson correlation coefficient ( $r$ ) measures the linear relationship between the satellite and the gauge estimates with range between -1 to +1 . Bias measures the extent to which satellite under/over estimates gauge observations. A bias value of 1 is a perfect score; bias value $>1$ is an overestimation whereas bias $<1$ is an underestimation. The mean difference measures the absolute difference between the means of the observations and the estimates.

Afterwards, daily rainfall fields for a total of 560 grid points over Ghana were extracted from the CHIRPS V2 data. The extracted rainfall data for each grid in the agro-ecological zones were subjected to a homogenization procedure with the aid of the RHtestsV4 package described in [24] [28] [29]. RHtestsV4 uses the so called two-phase regression model to detect change-points in each grid's time series. This model is described in detail in [30] ([29], and references therein). Thereafter, the five selected extreme rainfall indices namely, Consecutive Dry Days (CDD), Consecutive Wet Days (CWD), Number of heavy rainfall days (R10), Number of very heavy rainfall days (R20) and Annual wet-day rainfall total (PRCPTOT) (see Table 1) were computed for all grids in the agro-ecological zones using the homogenized rainfall data with the aid of the FClimdex software package. The mean climatology for the selected extreme rainfall indices for the number of grids and the period of study were computed for all the agro-ecological zones. The trends for the extreme rainfall indices were computed for all grids applying the Mann-Kendall (MK) test described in ([9], and references therein) [17] [31]. The significance of the trends was tested by computing the p-values which were compared to a predefined significant value of 0.05 . Grid points with p-values greater than 0.05 are non-significant whereas p-values less than 0.05 are considered significant.

Table 1. Selected rainfall indices (excerpt from the ETCCDI) analyzed over Ghana.

\begin{tabular}{ccc}
\hline Indices & Description & Units \\
\hline CDD & Consecutive dry days (rainfall $<1 \mathrm{~mm}$ ) & Days \\
CWD & Consecutive wet days (rainfall $>1 \mathrm{~mm})$ & Days \\
R10 $\mathrm{mm}$ & Number of heavy rainfall days (rainfall $>10 \mathrm{~mm})$ & Days \\
R20 mm & Number of very heavy rainfall days (rainfall $>20 \mathrm{~mm})$ & Days \\
PRCPTOT & Annual wet-day rainfall total & mm
\end{tabular}




\section{Results and Discussions}

\subsection{Validation of CHIRPS V2 Data (1998-2012)}

As a foremost step, the CHIRPS V2 rainfall data was assessed with reference to the GMet gridded gauge data (GGGD) based on monthly and seasonal time scales for a period of 1998-2012. In [24], it has been established that the GGGD gives a better representation of the rainfall patterns in Ghana than satellite and gauge-only gridded rainfall datasets at various spatio-temporal scales in the country. The GGGD owes its good quality to the relatively high dense (113) gauge stations over the country. However, these gauge distributions are comparatively low in numbers especially in the dry Savannah than in the rest of the agro-ecological zones (Transition, Forest and Coastal) and has a shorter time span. The mean monthly rainfall patterns observed from GGGD and CHIRPS V2 satellite product are displayed in Figure 2. A very good temporal agreement is observed between GGGD and CHIRPS V2 throughout the entire country except for few portions with some relatively small disparities. Nonetheless, in order to ascertain the quantum of differences between these products, the Pearson correlation ( $r$ ) and the Bias statistical measures are computed on a seasonal scale over the country for the period of study. The Pearson correlation which measures the strength of association or relationship between the products for the four seasons thus, December-January (DJF), March-May (MAM), June-August (JJA) and September-November (SON) is shown in Figure 3.

CHIRPS is observed to show a very good agreement $(0.64-0.84)$ with gauge during the DJF season especially over the Transition, Forest and Coastal zones of the country. On the other hand, relatively poor agreement $(0.20-0.60)$ was observed between the products in the dry Savannah. CHIRPS for the MAM season showed good correspondence with gauge with $r$ values ranging between, 0.40 0.90 especially for all but some portions of the Transition zone which showed

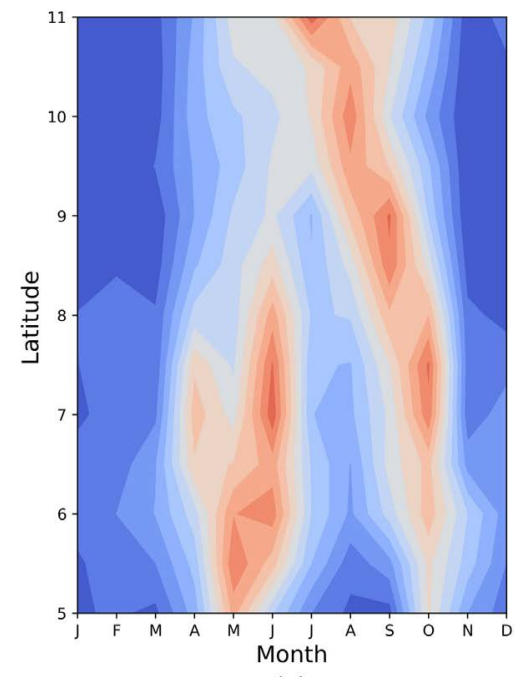

(a)

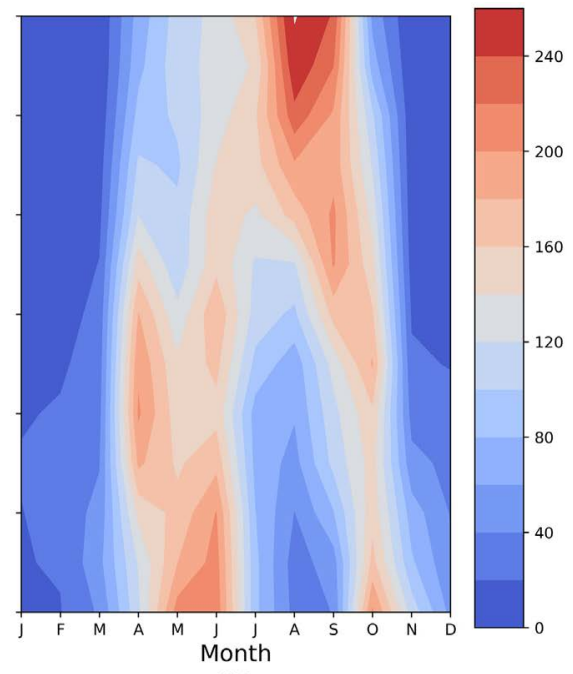

(b)

Figure 2. Inter-comparison of zonal mean rainfall over Ghana from GMet gauge data (a) and CHIRPS (b) for the period of 1998-2012. 

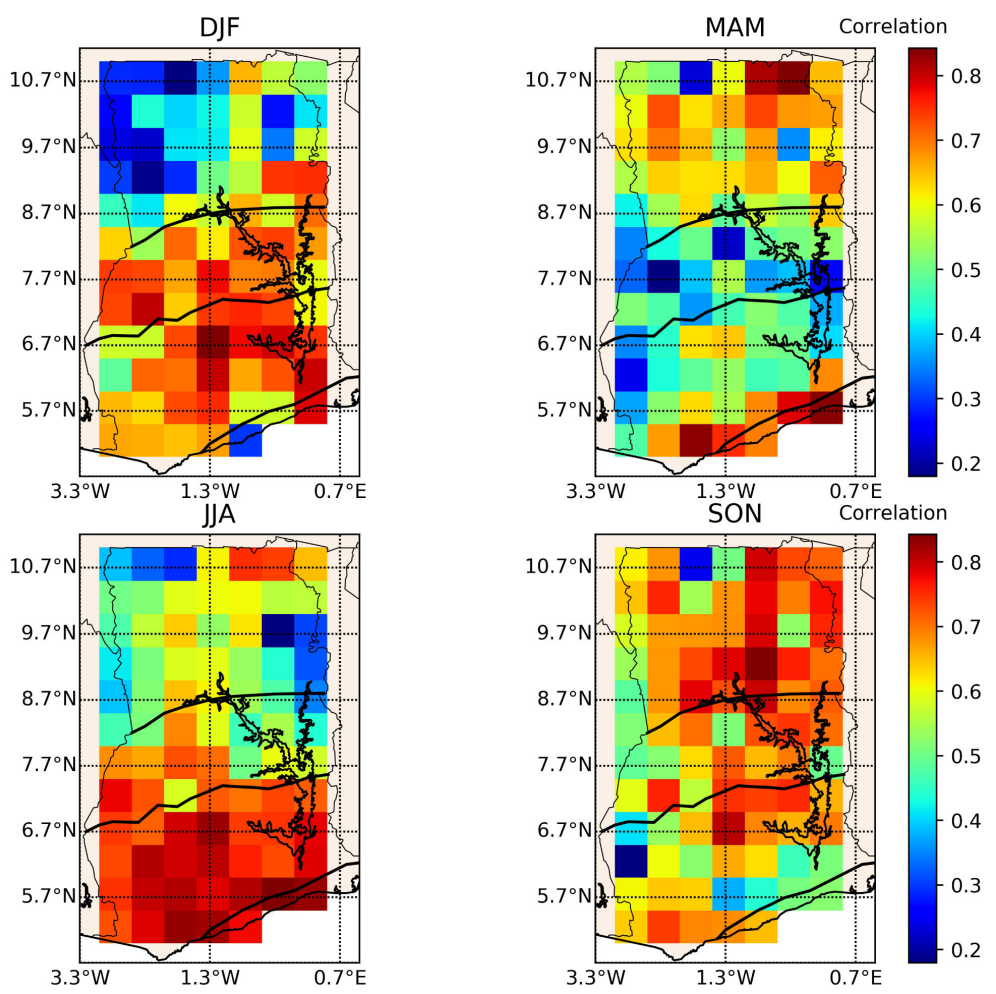

Figure 3. Pearson Correlation between GGGD and CHIRPS for the four seasons, DJF, MAM, JJA and SON throughout the entire country for the period of 1998-2012.

relatively weak $\mathrm{r}$ values $\leq 0.40$. Similar to observations during the DJF season, all zones except for parts of Northwestern and Northeastern parts of Savannah zone showed relatively low $r$ values (with $r$ values $\leq 0.40$ ) in the JJA season. On average, CHIRPS is revealed to have a good agreement with GGGD in all agro-ecological zones during the SON season. The bias plots between GGGD and CHIRPS in the four seasons in Figure 4 have revealed relatively high bias values in the DJF season which is an indication of overestimation of rainfall by CHIRPS for most grids (see Section 3). For the MAM season, relatively low bias values $(0.0-1.6)$ are seen to dominate almost all grids in the country except for some few grids in the Savannah zone of the country with high bias values (2.6 7.2). Similarly, for the JJA season, CHIRPS is observed to generally show relatively low bias values $(0.0-2.0)$ throughout the entire country except for a single grid in the eastern coast of the country which is possibly as a result of some interpolation errors at the boundaries. Similar to observations in the DJF season, there is generally a good agreement between the products throughout the country except for some portions northeast of the Savannah zone of the country in the SON season.

The mean seasonal rainfall patterns and mean difference between CHIRPS and gauge over the four agro-ecological zones are represented in Figure 5. CHIRPS is observed to capture the seasonal rainfall patterns in the agro-ecological zones considerably well (see Figure 5(a) and Figure 5(b)). However, from the mean difference in Figure 5(c), CHIRPS overestimates $(>10 \mathrm{~mm})$ gauge in the 

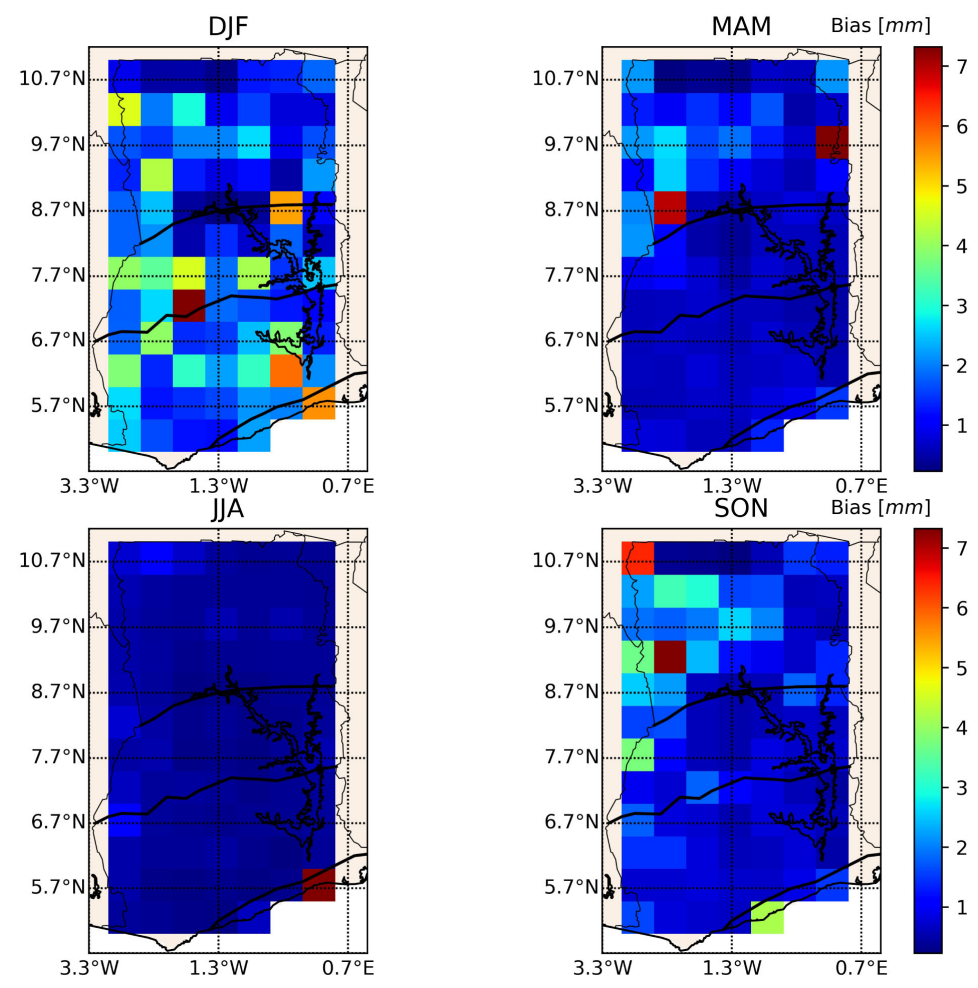

Figure 4. Bias between GGGD and CHIRPS for the four seasons, DJF, MAM, JJA and SON throughout the entire country for the period of 1998-2012.

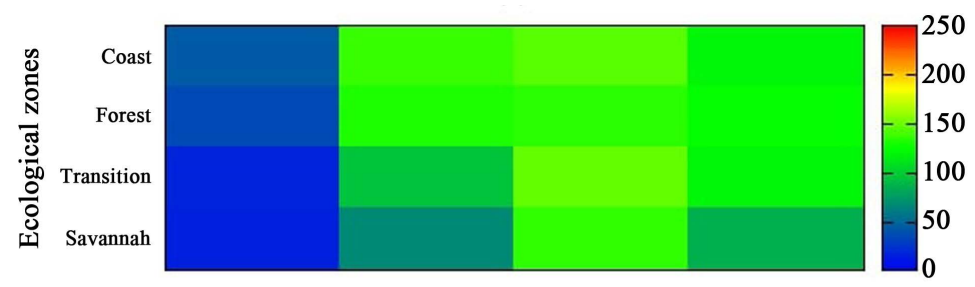

(a)

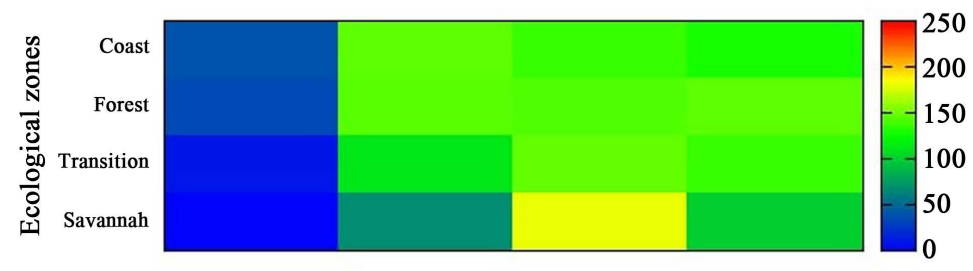

(b)

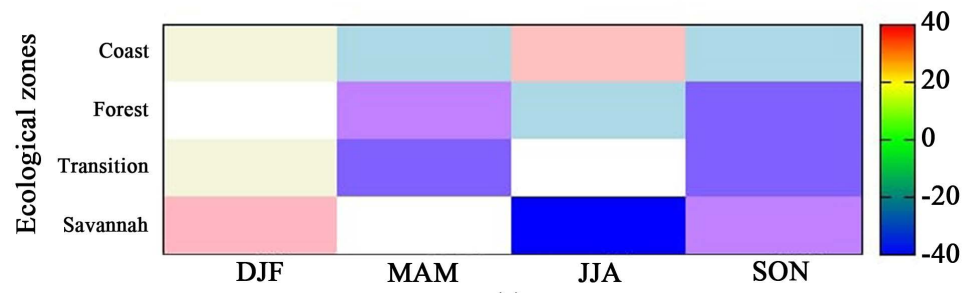

(c)

Figure 5. Mean seasonal rainfall for gauge (a), CHIRPS (b) and the mean difference between GGGD and CHIRPS (c) throughout the entire country for the period of 1998-2012. 
JJA and SON seasons over the Savannah zone of the country. During the DJF season on the other hand, CHIRPS is observed to slightly underestimate gauge $(<10$ $\mathrm{mm})$. Slight overestimation is observed during the MAM and SON seasons in the Transition zone. Over the Forest zone, there is generally a slight overestimation of rainfall throughout the seasons except for the dry season (DJF). CHIRPS is observed to fairly capture rainfall well throughout the seasons in the Coastal zone except for slight under/over estimations in some cases.

\subsection{Mean Seasonal Rainfall Variability in Ghana}

The mean seasonal rainfall patterns over Ghana are shown in Figure 6. The DJF season happens to be the driest season throughout the entire country. Relatively high rainfall amounts ranging between $60-80 \mathrm{~mm}$ dominates the southwestern parts of the country in this season. The remaining parts of southern portions of the country have rainfall values between $20-80 \mathrm{~mm}$. The lowest rainfall values $(\leq 20 \mathrm{~mm})$ are recorded over the upper Transition and Savannah zones of the country which is similar to observations in [9]. This dryness in the DJF season is as a result of the intensification of the Azores pressure (AP) (located about $30^{\circ} \mathrm{N}$ of Atlantic) and the weakening of the St. Helena (SH) (located about $25^{\circ} \mathrm{S}$ of Atlantic). The pressure patterns in these zones results in the prevalence of northeasterly trade winds (dry and dusty in nature) over the entire country thus causing the Inter-tropical Convergence Discontinuity (ITD) to migrate southward beyond Ghana.
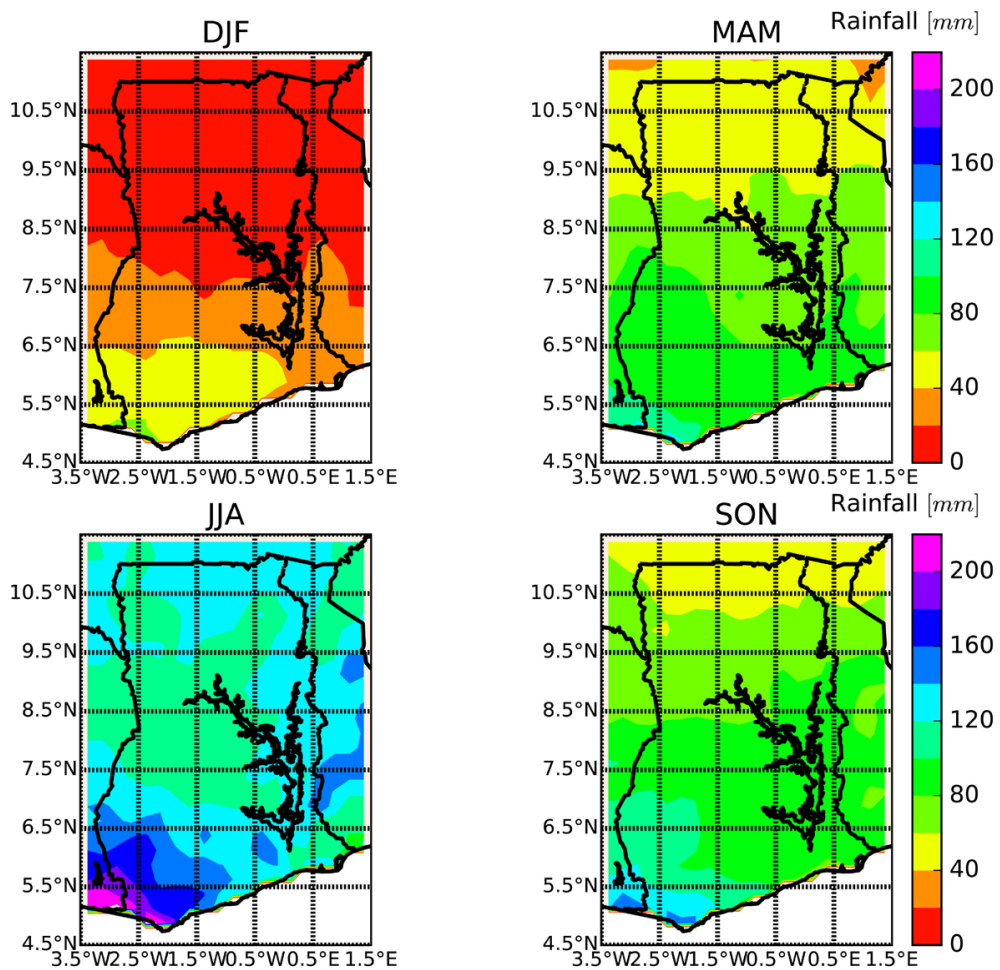

Figure 6. Mean seasonal rainfall climatology over the country for the period of 1981-2015. 
The MAM season is considered the rainfall onset period for most parts of the country. Rainfall values ranges between $60-200 \mathrm{~mm}$ throughout the entire country with low values dominating the Savannah zone and parts of the Transition zone whereas high values on the other hand dominate the south especially southwestern portions of the county. During the MAM season, the AP begins to weaken whilst the SH intensifies. Consequently, the southwest trade winds which are moisture laden begin to prevail over the dry north-easterlies thereby causing the ITD to migrate from its initial southern position to a more northward position thus, sweeping moisture into the southern parts of the country. The JJA on the other hand, happens to be the wettest period of the year throughout the country. Rainfall values ranges between $100-220 \mathrm{~mm}$. The western coasts of the country are observed to record the highest rainfall values which range between 140 - 220 $\mathrm{mm}$. The Savannah zone of the country is observed to record rainfall amounts in the range of $100-120 \mathrm{~mm}$ whereas the remainder of the country recorded an average value of about $140 \mathrm{~mm}$. During this season, the AP becomes very weak whereas the $\mathrm{SH}$ becomes very intense thereby triggering the dominance of the southwest moisture laden trade winds over the entire country. This results to the migration of the ITD further north thus, releasing moisture over most parts of the country.

The SON rainfall season is considered the minor rainfall season especially for the southern parts of the country. Rainfall amounts varies from low values of 40 - $60 \mathrm{~mm}$ far north and far eastern coasts of the country and medium range values of about $60-100 \mathrm{~mm}$ over the central portions of the country and high values in the range of $100-180 \mathrm{~mm}$ over the southwestern parts. Around this period, the SH now begins to weaken while the AP begins to intensify, thus the strength of the monsoon winds begins to weaken thereby triggering the return of the ITD [9] [22].

\subsection{Trends of Rainfall Indices in Ghana}

In this section, the rainfall indices namely, CWD, CDD, R10 mm, R20 mm and PRCPTOT were computed with the aid of the FClimDex software over the four agro-ecological zones of the country. Thereafter, the trends and significance of these trends were further tested. The results for these analyses are discussed in this section.

\subsubsection{Trend Analysis of Consecutive Dry Days (CDD)}

Figure 7 displays the trends of consecutive dry days in the four agro-ecological zones of Ghana for the period of 1981-2015. CDD defines the annual count of the maximum number of consecutive days with rainfall values $<1 \mathrm{~mm}$. Positive trends of CDD are observed over the Transition, Forest and Coastal zones of the country. This increasing trend is further observed to be more pronounced in the Transition zone $(0.103 \mathrm{~mm}$ per year), followed by the Forest zone $(0.098 \mathrm{~mm}$ per year) then lastly, the Coastal zone $(0.07 \mathrm{~mm}$ per year). The Savannah zone on the other hand is noted to experience a strong negative trend $(-0.58 \mathrm{~mm}$ per 

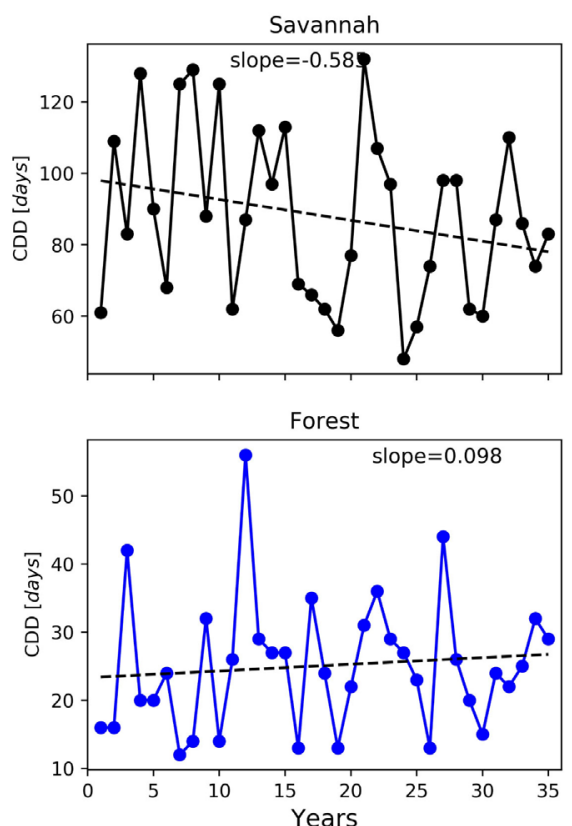
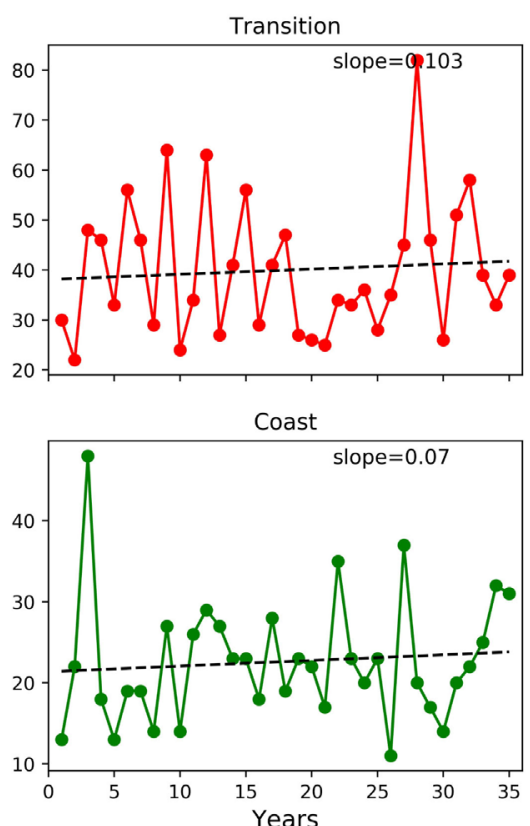

Figure 7. Trends of Consecutive Dry Days (CDD) over the four agro-ecological zones of Ghana for the period of 1981-2015.

year) of consecutive dry days throughout the period of investigation similar to observations in [17]. The significance of these trends were further investigated and observed to be significant in all agro-ecological zones at a confidence interval of $95 \%$.

\subsubsection{Trend Analysis of Consecutive Wet Days (CWD)}

CWD is defined as the annual count of the maximum number of consecutive days with rainfall values $>1 \mathrm{~mm}$ [17]. Decreasing trends of consecutive wet days are observed over the Savannah $(-0.156 \mathrm{~mm}$ per year), Transition $(-0.220$ $\mathrm{mm}$ per year) and Coastal zones $(-0.147 \mathrm{~mm}$ per year) of the country (see Figure 8). This implies that, the number of consecutive wet days is beginning to depreciate over the years in these three zones. This is especially serious for people in the Savannah zone since they predominantly depend on farming for their livelihood. The Forest zone which is mostly the wettest in the country throughout the year is observed to show slight increasing trend $(0.104 \mathrm{~mm}$ per year) of CWD.

\subsubsection{Trend Analysis of Number of Heavy Rainfall Days (R10 mm)}

The number of heavy rainfall days is the annual count of days when the rainfall values are $>10 \mathrm{~mm}$. From Figure 9, it is observed that, both the Savannah and Transition zones show weak increasing trends of 0.100 and 0.092 per year respectively. An almost steady-increasing trend $(0.011 \mathrm{~mm}$ per year) of the number of heavy rainfall days is observed over the Forest zone whilst on the other hand, a rather steady-decreasing trend $(-0.055 \mathrm{~mm}$ per year) is observed in the Coastal zone of the country which is consistent with findings in [9] [17]. 

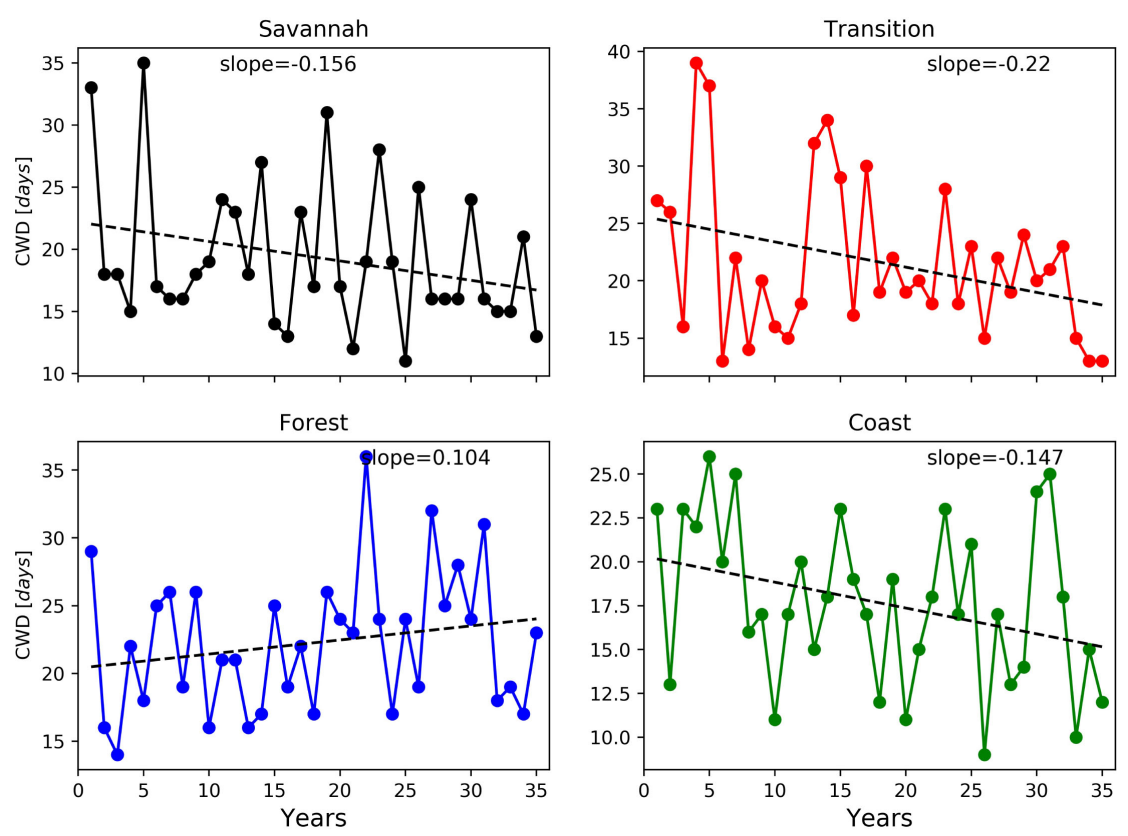

Figure 8. Trends of Consecutive Wet Days (CWD) over the four agro-ecological zones of Ghana for the period of 1981-2015.
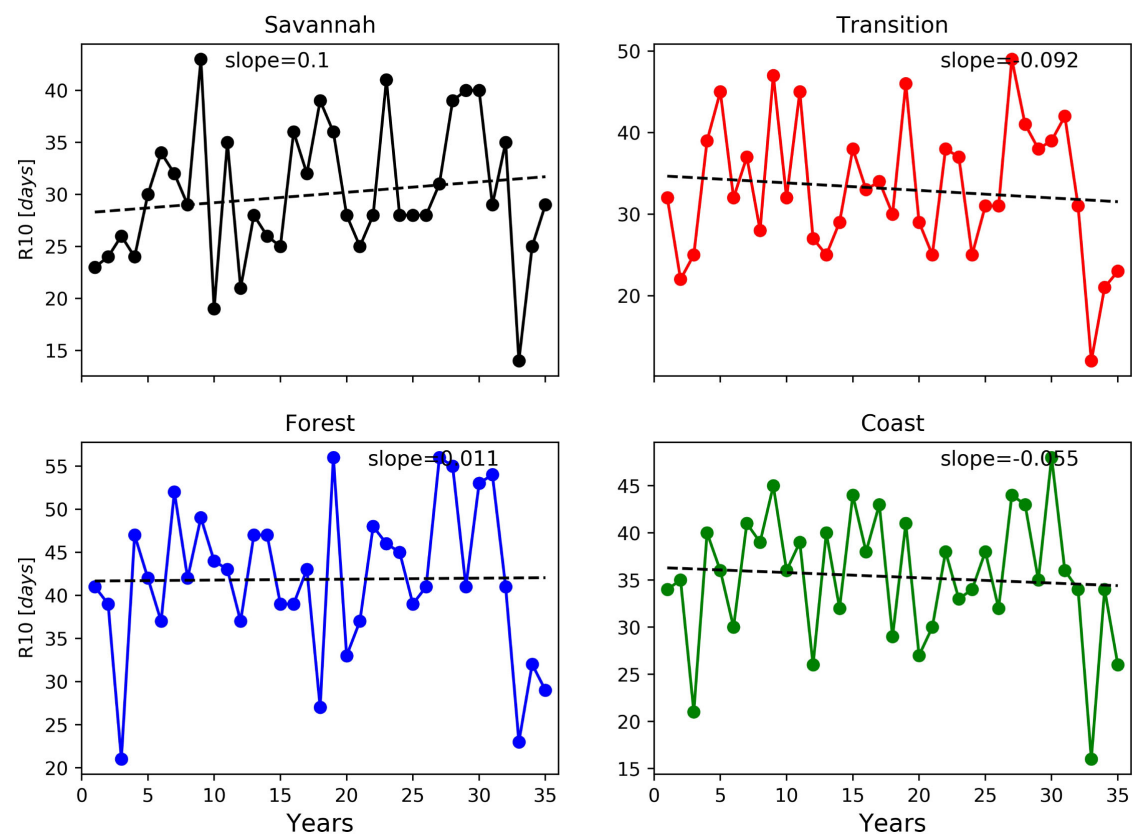

Figure 9. Trends of the number of heavy rainfall days $(\mathrm{R} 10 \mathrm{~mm})$ over the four agro-ecological zones of Ghana for the period of 1981-2015.

\subsubsection{Trend Analysis of Number of Very Heavy Rainfall Days (R20 mm)}

The number of very heavy rainfall which defines the annual count of days when the rainfall values are $>20 \mathrm{~mm}$ is observed to show weak increasing trends in all agro-ecological zones except in the Transition zone of the country (see Figure 10). These findings support results reported in [17]. The number of very heavy rainfall is observed to show a steady trend in the Transition zone of the country. 

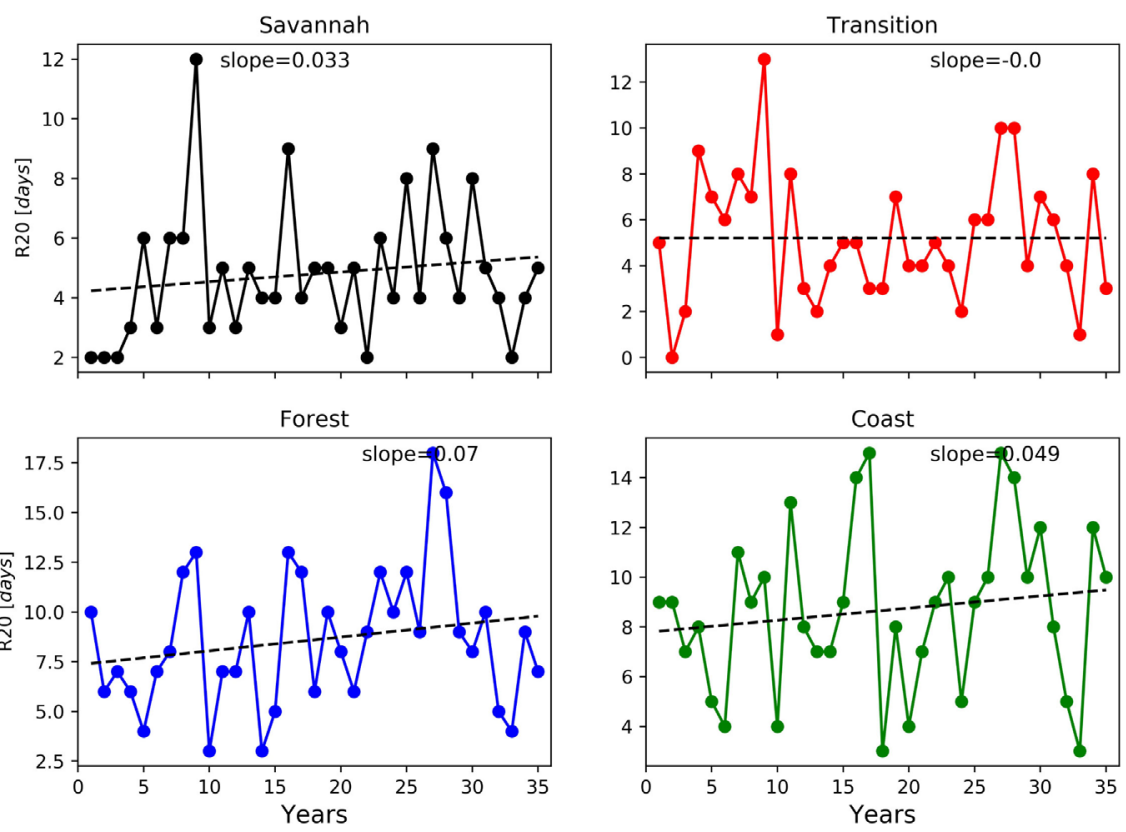

Figure 10. Trends of the number of very heavy rainfall days (R20 $\mathrm{mm}$ ) over the four agro-ecological zones of Ghana for the period of 1981-2015.

\subsubsection{Trend Analysis of Annual Wet-Day Rainfall Total (PRCPTOT)}

The annual wet-day rainfall total is the annual total number of days when rainfall is $>1 \mathrm{~mm}$. From Figure 11, it is observed that the annual wet day rainfall totals have increasing trend in the Savannah and Forest zones of the country whereas decreasing trends dominate the remaining zones which is in consistence with findings in [17]. The increasing trends are more pronounced in the Savannah zone (1.268 mm per year) followed by the Forest zone (1.088 $\mathrm{mm}$ per year) whilst the decreasing trend is more pronounced in the Coastal zone $(-1.308 \mathrm{~mm}$ per year) followed by the Transition zone $(-0.987 \mathrm{~mm}$ per year).

\section{Conclusions}

The seasonal and annual rainfall variability over the four agro-ecological zones of Ghana has been analyzed in this study using the satellite-based CHIRPS V2 rainfall time series covering the period of 1981-2015. The results for the validation revealed a good agreement $(r>0.7)$ between CHIRPS and observations in almost the entire country. However, CHIRPS showed great biases $(r \leq 0.24)$ from gauge in the DJF season over parts of the Northeastern (NE) portions of the country and parts of the Forest and Transition zones in the MAM season. On average, the product is revealed to show a very good agreement with gauge especially in the minor rainfall season (SON) over the entire country. The mean difference between gauge and CHIRPS is relatively high in the DJF season. CHIRPS is observed in the JJA season to greatly over-estimate gauge in the Savannah zone. The CHIRPS satellite rainfall data revealed diverse performance depending on the season and location.

The mean seasonal rainfall climatology over the country is observed to be in 

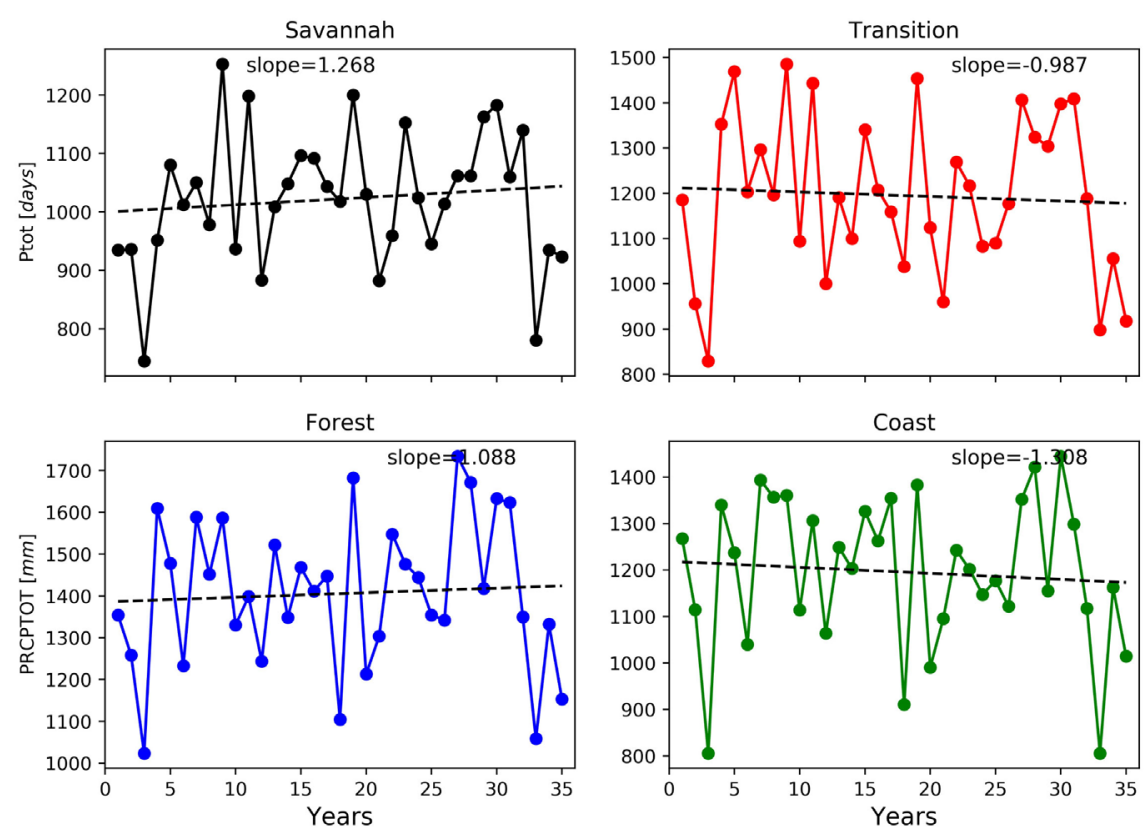

Figure 11. Trends of the annual precipitation total (PRCPTOT) over the four agro-ecological zones of Ghana for the period of 1981-2015.

the range of $20-80 \mathrm{~mm}, 60-200 \mathrm{~mm}, 100-220 \mathrm{~mm}$ and $40-180 \mathrm{~mm}$ in the DJF, MAM, JJA and SON seasons respectively with high intensities of rainfall dominated over the Southwestern portions of the country in all seasons. The consecutive dry days are observed to have range, 12 - 130 days per year, 20 - 80 days per year, 12 - 58 days per year and 10 - 48 days per year in the Savannah, Transition, Forest and Coastal zones respectively. For the consecutive wet days, the Forest zone as expected is observed to have relatively high frequencies followed by Transition zone then the Coastal zone and lastly, the Savannah zone. The number of heavy rainfall days on the other hand was observed to have ranges, 13 - 43 days per year, 12 - 50 days per year, 20 - 55 days per year and 15 48 days per year respectively in the Savannah, Transition, Forest and Coastal zones of the country. The frequencies of the number of very heavy rainfall days in the country were in the range of $2-12$ days per year, 0 - 13 days per year, 3 18 days per year and $3-15$ days per year respectively in the Savannah, Transition, Forest and Coastal zones of the country. The annual wet-day rainfall total over the country was observed to have high intensities in the Forest zone with range, $1000-18,000 \mathrm{~mm}$ followed by the Transition zone with range, $825-1500$ $\mathrm{mm}$ then the Coastal zone with range, $800-1450 \mathrm{~mm}$ and lastly the Savannah zone with range, $750-1250 \mathrm{~mm}$.

The trend analysis revealed positive trends of CDD in the Transition, Forest and Coastal zones and a negative trend in the Savannah zone of the country. Decreasing trends of consecutive wet days are observed over the Savannah, Transition and Coastal zones whereas increasing trends are observed in the Savannah zone of the country. Weak increasing trends in the number of very heavy rainfall days are observed all over the agro-ecological zones except in the Transi- 
tion zone. It is observed that the annual wet day rainfall total have increasing trend in the Savannah and Forest zones of the country whereas decreasing trends dominate the remainder of the zones which is consistent with findings in [9].

The findings in this study have adverse effects on rain-fed agricultural practices, water resource management and food security over the country.

\section{Acknowledgements}

The first author acknowledges support of the Organization of Women in Science for the Developing World (OWSD) sandwich programme and Botswana International University of Science and Technology (BIUST) for hosting and the teaching assistantship during her stay in Botswana.

\section{Conflicts of Interest}

The authors declare no conflict of interest.

\section{References}

[1] Antwi-Agyei, P., Fraser, E.D.G., Dougill, A.J., Stringer, L.C. and Simelton, E. (2012) Mapping the Vulnerability of Crop Production to Drought in Ghana Using Rainfall, Yield and Socioeconomic Data. Applied Geography, 32, 324-334.

https://doi.org/10.1016/j.apgeog.2011.06.010

[2] Fauset, S., Baker, T.R., Lewis, S.L., Feldpausch, T.R., Affum-Baffoe, K., Foli, E.G., Hamer, K.C. and Swaine, M.D. (2012) Drought Induced Shifts in the Floristic and Functional Composition of Tropical Forests in Ghana. Ecology Letters, 15, 1120-1129. https://doi.org/10.1111/j.1461-0248.2012.01834.x

[3] Armah, F.A., Yawson, D.O., Yengoh, G.T., Odoi, J.O. and Afrifa, E.K.A. (2010) Impact of Floods on Livelihoods and Vulnerability of Natural Resource Dependent Communities in Northern Ghana. Water, 2, 120-139. https://doi.org/10.3390/w2020120

[4] Adiku, S.G.K., Dayananda, P.W.A., Rose, C.W. and Dowuona, G.N.N. (1997) An Analysis of the Within-Season Rainfall Characteristics and Simulation of the Daily Rainfall in Two Savanna Zones in Ghana. Agricultural and Forest Meteorology, 86, 51-62. https://doi.org/10.1016/S0168-1923(96)02414-8

[5] Rademacher-Schulz, C., Schraven, B. and Mahama, E.S. (2014) Time Matters: Shifting Seasonal Migration in Northern Ghana in Response to Rainfall Variability and Food Insecurity. Climate and Development, 6, 46-52. https://doi.org/10.1080/17565529.2013.830955

[6] Owusu, K., Waylen, P. and Qiu, Y. (2008) Changing Rainfall Inputs in the Volta Basin: Implications for Water Sharing in Ghana. GeoJournal, 71, 201-210. https://doi.org/10.1007/s10708-008-9156-6

[7] Nkrumah, F., Klutse, N.A.B., Adukpo, D.C., Owusu, K., Quagraine, K.A., Owusu, A. and Gutowski, W. (2014) Rainfall Variability over Ghana: Model versus Rain Gauge Observation. International Journal of Geosciences, 5, 673. https://doi.org/10.4236/ijg.2014.57060

[8] Ofori-Sarpong, E. (2001) Impact of Climate Change on Agriculture and Farmers Coping Strategies in the Upper East Region of Ghana. West African Journal of Applied Ecology, 2, 21-35. 
[9] Baidu, M., Amekudzi, L.K., Aryee, J.N.A. and Annor, T. (2017) Assessment of Long-Term Spatio-Temporal Rainfall Variability over Ghana Using Wavelet Analysis. Climate, 5, 30. https://doi.org/10.3390/cli5020030

[10] Amikuzino, J. and Donkoh, S.A. (2012) Climate Variability and Yields of Major Staple Food Crops in Northern Ghana. African Crop Science Journal, 20, 349-360.

[11] FAO AQUASTAT (2005) Aquastat Database.

[12] Lacombe, G., McCartney, M. and Forkuor, G. (2012) Drying Climate in Ghana over the Period 1960-2005: Evidence from the Resampling-Based Mann-Kendall Test at Local and Regional Levels. Hydrological Sciences Journal, 57, 1594-1609. https://doi.org/10.1080/02626667.2012.728291

[13] Lawrence Dingman, S. (2015) Physical Hydrology. Waveland Press, Long Grove.

[14] Dinku, T., Ceccato, P., Grover-Kopec, E., Lemma, M., Connor, S.J. and Ropelewski, C.F. (2007) Validation of Satellite Rainfall Products over East Africa's Complex Topography. International Journal of Remote Sensing, 28, 1503-1526. https://doi.org/10.1080/01431160600954688

[15] Owusu, K. and Waylen, P. (2009) Trends in Spatio-Temporal Variability in Annual Rainfall in Ghana (1951-2000). Weather, 64, 115-120. https://doi.org/10.1002/wea.255

[16] Owusu, K. and Waylen, P.R. (2013) The Changing Rainy Season Climatology of Mid-Ghana. Theoretical and Applied Climatology, 112, 419-430. https://doi.org/10.1007/s00704-012-0736-5

[17] Manzanas, R., Amekudzi, L.K., Preko, K., Herrera, S. and Gutiérrez, J.M. (2014) Precipitation Variability and Trends in Ghana: An Intercomparison of Observational and Reanalysis Products. Climatic Change, 124, 805-819. https://doi.org/10.1007/s10584-014-1100-9

[18] Diem, J.E., Ryan, S.J., Hartter, J. and Palace, M.W. (2014) Satellite-Based Rainfall Data Reveal a Recent Drying Trend in Central Equatorial Africa. Climatic Change, 126, 263-272. https://doi.org/10.1007/s10584-014-1217-x

[19] New, M., Todd, M., Hulme, M. and Jones, P. (2001) Precipitation Measurements and Trends in the Twentieth Century. International Journal of Climatology: A Journal of the Royal Meteorological Society, 21, 1889-1922. https://doi.org/10.1002/joc.680

[20] Rodda, J.C. and Dixon, H. (2012) Rainfall Measurement Revisited. Weather, 67, 131-136. https://doi.org/10.1002/wea.875

[21] Schreck, C.J. and Semazzi, F.H.M. (2004) Variability of the Recent Climate of Eastern Africa. International Journal of Climatology, 24, 681-701. https://doi.org/10.1002/joc.1019

[22] Amekudzi, L.K., Yamba, E.I., Preko, K., Asare, E.O., Aryee, J., Baidu, M. and Codjoe, S.N.A. (2015) Variabilities in Rainfall Onset, Cessation and Length of Rainy Season for the Various Agro-Ecological Zones of Ghana. Climate, 3, 416-434. https://doi.org/10.3390/cli3020416

[23] Asante, F.A. and Amuakwa-Mensah, F. (2014) Climate Change and Variability in Ghana: Stocktaking. Climate, 3, 78-99. https://doi.org/10.3390/cli3010078

[24] Aryee, J.N.A., Amekudzi, L.K., Quansah, E., Klutse, N.A.B., Atiah, W.A. and Yorke, C. (2017) Development of High Spatial Resolution Rainfall Data for Ghana. International Journal of Climatology, 38, 1201-1215. https://doi.org/10.1002/joc.5238

[25] Trejo, F.J.P., Barbosa, H.A., Peñaloza-Murillo, M.A., Moreno, M.A. and Farías, A. (2016) Intercomparison of Improved Satellite Rainfall Estimation with Chirps Grid- 
ded Product and Rain Gauge Data over Venezuela. Atmósfera, 29, 323-342. https://doi.org/10.20937/ATM.2016.29.04.04

[26] Bayissa, Y., Tadesse, T., Demisse, G. and Shiferaw, A. (2017) Evaluation of Satellite-Based Rainfall Estimates and Application to Monitor Meteorological Drought for the Upper Blue Nile Basin, Ethiopia. Remote Sensing, 9, 669. https://doi.org/10.3390/rs9070669

[27] Funk, C., Peterson, P., Landsfeld, M., Pedreros, D., Verdin, J., Shukla, S., Husak, G., Rowland, J., Harrison, L., Hoell, A., et al. (2015) The Climate Hazards Infrared Precipitation with Stations-A New Environmental Record for Monitoring Extremes. Scientific Data, 2, Article ID: 150066. https://doi.org/10.1038/sdata.2015.66

[28] Wang, X.L. (2003) Comments on "Detection of Undocumented Change Points: A Revision of the Two-Phase Regression Model". Journal of Climate, 16, 3383-3385. https://doi.org/10.1175/1520-0442(2003)016<3383:CODOUC>2.0.CO;2

[29] Wang, X.L. and Feng, Y. (2010) Rhtestsv3 User Manual. Climate Research Division. Atmospheric Science and Technology Directorate. Science and Technology Branch, Environment Canada, 24.

[30] Lund, R. and Reeves, J. (2002) Detection of Undocumented Changepoints: A Revision of the Two-Phase Regression Model. Journal of Climate, 15, 2547-2554. https://doi.org/10.1175/1520-0442(2002)015<2547:DOUCAR>2.0.CO;2

[31] Tsidu, G.M. (2017) Secular Spring Rainfall Variability at Local Scale over Ethiopia: Trend and Associated Dynamics. Theoretical and Applied Climatology, 130, 91-106. https://doi.org/10.1007/s00704-016-1849-z 